\title{
Highly sensitive light-up near-infrared fluorescent probe for detection and imaging of $\beta$-glucuronidase in human serum, living cells and tumor-bearing mice
}

\author{
Xin Zhou ${ }^{1 \dagger}$, Deping Wang ${ }^{1 \dagger}$, Zhiyuan $\mathrm{Gao}^{2}$, Mingyue $\mathrm{He}^{1}$, Jiayi Hou ${ }^{1,3}$, Hui Zhang ${ }^{{ }^{*}}$, Guoqiang Zhang ${ }^{2 *}$, \\ Dan Ding ${ }^{2}$ and Guangxue Feng ${ }^{*}$
}

\begin{abstract}
Glucuronidase (GUS) plays a key role in tumor initiation, metastasis, and progression, and thus, has been proposed as a promising cancer biomarker. In this study, we designed an enzyme-activatable near-infrared (NIR) fluorescent probe (DCM- $\beta$ GICA) for the rapid and accurate detection of GUS activity in vitro, in vivo and ex vivo. The DCM$\beta G I c A$ was prepared by linking a glucuronic acid residue to dicyanomethylene-4H-pyran (DCM). This probe exhibited significant light-up NIR fluorescent signals at $680 \mathrm{~nm}$ after reacting with GUS and the Stokes shift could reach $150 \mathrm{~nm}$. The DCM- $\beta$ GlcA showed a high sensitivity toward GUS and an excellent linear relationship at concentrations ranging between 0 and $4 \mathrm{U} \mathrm{L}^{-1}\left(R^{2}=0.9974\right)$ with the limit of detection as low as $0.19 \mathrm{U} \mathrm{L}^{-1}$. We used the DCM- $\beta$ GlcA to identify GUS serum levels in both cancer patients and healthy individuals with a similar accuracy as that of an enzyme-linked immunosorbent assay (ELISA) while being easier and faster to perform. Moreover, the DCM- $\beta$ GlcA was used for tracking endogenous GUS in living cells, thereby discriminating GUSoverexpressed liver cancer from normal cells. Additionally, the DCM- $\beta$ GIcA was able to detect and image endogenous GUS in liver cancer tissue and tumor-bearing mouse models. These findings demonstrate the potential of the DCM- $\beta$ GlcA as a promising tool for detecting and monitoring GUS activity in preclinical applications.
\end{abstract}

Keywords: NIR fluorescent probe, $\beta$-glucuronidase, serum detection, cell imaging, in-vivo bioimaging

\section{INTRODUCTION}

Cancer is ranked as a major cause of death worldwide, second only to cardiovascular diseases. One of the reasons associated with high mortality rates in cancer patients is late diagnosis, resulting in delayed treatment [1]. To improve patient survival, tumor biomarkers, such as tumor-associated enzymes, have been widely used for the early diagnosis and clinical treatment of cancer [2]. $\beta$-Glucuronidase (GUS), a member of the lysosomal glycosidase family, can hydrolyze the glucuronide bond at the non-reducing termini of glycosaminoglycans, thereby leading to the degradation of proteoglycans and the destruction of extracellular matrix, which ultimately facilitates tumor invasion and metastasis [3,4]. Abnormal GUS overexpression is associated with the development of various cancers, including liver cancer [5], gastric cancer [6], colon cancer [7], and pancreatic adenocarcinoma [8]. Thus, GUS has been regarded as a tumor biomarker $[9,10]$. Based on the biological functions of GUS, detecting its activity in vitro and in vivo is necessary for early diagnosis, real-time imaging, and therapeutic evaluation of tumors.

Several methods have been used for the detection of GUS bioactivity, including colorimetric assays [11], magnetic resonance imaging (MRI) [12], and positron emission tomography (PET) [13]. Among them, colorimetric assay represents the standard method and is commonly used in clinical setting [14]. However, the detection sensitivity of this method is low and the use of certain substances, for example, autoantibodies and heterophilic antibodies, may lead to inaccurate assessment of serum GUS levels [15]. To improve the detection accuracy, a fluorescence technique has been used to detect the activity of GUS with high sensitivity and selectivity, excellent biocompatibility, and easy operation. Currently, numerous types of fluorescent probes have been reported, which are useful for monitoring the GUS activity in serum, cells, and tissues [15-22]. However, most of them cannot be used for in vivo imaging owing to their short emission wavelengths $(<600 \mathrm{~nm})$, which cause strong background interference arising from inferior tissue penetration and high tissue autofluorescence, and in turn lead to imprecise reflection of the activity of a target enzyme in vivo.

Near-infrared (NIR) fluorescence imaging can reduce autofluorescence and optical absorption in tissue, thus, resulting in high penetration depth and sensitivity $[23,24]$. Moreover, spe-

\footnotetext{
${ }^{1}$ College of Medical Imaging, and Key Laboratory of Cellular Physiology, Ministry of Education, Shanxi Medical University, Taiyuan 030001, China

${ }^{2}$ Key Laboratory of Bioactive Materials Ministry of Education, College of Life Sciences, and State Key Laboratory of Medicinal Chemical Biology, Nankai University, Tianjin 300071, China

${ }^{3}$ Department of Clinical Laboratory, Shanxi Provincial Academy of Traditional Chinese Medicine, Taiyuan 030001, China

${ }^{4}$ AIE Institute, State Key Laboratory of Luminescent Materials and Devices, Guangdong Provincial Key Laboratory of Luminescence from Molecular Aggregates, School of Materials Science and Engineering, South China University of Technology, Guangzhou 510640, China

These authors contributed equally to this work.

* Corresponding authors (emails: fenggx@scut.edu.cn (Feng G); guoqiangzhang@mail.nankai.edu.cn (Zhang G); zhang_hui@sxmu.edu.cn (Zhang H))
} 
cific light-up NIR probes could further noninvasively monitor the molecules or biologic activities of tumor microenvironment in real time, such as $\mathrm{pH}$ [25], hydrogen peroxide [26], biomarker expression levels [27], and even PD-L1 expression level and immune cell status [28], which provide accurate predictions for immunotherapeutic response. Until recently, only a few "TurnOn" fluorescent probes have been used for NIR fluorescence in vivo imaging of GUS [20-22]. These NIR fluorescent probes have also realized the imaging of GUS activity in living cells, but have not been applied to the serum GUS detection for cancer patients. At present, serum assay is still the main method for biomarker detection, especially accurate detection of tumor markers at low concentrations, which facilitates early diagnosis and therapeutic monitoring of cancer [29,30]. In addition, a large Stokes shift is beneficial for improving the measurement accuracy though preventing the self-quenching and reducing autofluorescence [31]. Therefore, an NIR fluorescent probe with large Stokes shift is very urgent for sensitive and accurate detection of endogenous GUS in serum and other living biological samples.

In this study, we report a GUS-targeting light-up NIR fluorescent probe with large Stokes shift capable of detecting the GUS activity in human serum, living cells and mouse tumor models, which in turn clarifies its potential role in tumor diagnosis (Scheme 1). This probe, DCM- $\beta$ GlcA, was designed through the conjugation of an enzyme-selective recognition unit with a dicyanomethylene- $4 H$-pyran (DCM) chromophore, which was used as the fluorogenic reporter owing to its excellent sensing properties $[32,33]$. In the presence of GUS, the probe exhibited a dramatic increase in fluorescence in the NIR region. Using this probe, an assay was performed to detect GUS in human serum from both cancer patients and healthy individuals. In addition, DCM- $\beta$ GlcA implements direct and accurate monitoring of the intracellular distribution of endogenous GUS, which allows for in situ visualization of GUS activity in a mouse tumor model.

\section{EXPERIMENTAL SECTION}

\section{Synthesis of DCM- $\beta$ GIcA}

The synthetic route of DCM- $\beta$ GlcA is shown in Scheme 2 . The starting substrate Ac- $\beta$ GlcA-Ph-CHO (102 mg, $0.23 \mathrm{mmol}$, 1 equiv) was dissolved in $5 \mathrm{~mL}$ of acetonitrile (ACN) followed by the addition of piperidine $(46 \mu \mathrm{L}, 0.47 \mathrm{mmol}, 2$ equiv) and dicyanomethyl chromone (DCMC) $(72.7 \mathrm{mg}, 0.35 \mathrm{mmol}$, 1.5 equiv). The reaction mixture was stirred at $80^{\circ} \mathrm{C}$ for $3 \mathrm{~h}$ and monitored by thin layer chromatography (TLC, petroleum ether/ethyl acetate (PE:EA) = 5:2). Upon completion, the reaction mixture diluted with EA $(100 \mathrm{~mL})$ was washed with saturated solution of $0.5 \mathrm{~mol} \mathrm{~L}^{-1} \mathrm{HCl}(100 \mathrm{~mL})$. The organic layer was separated, washed with brine, dried over $\mathrm{Na}_{2} \mathrm{SO}_{4}$ and evaporated under reduced pressure. The orange residue was purified by column chromatography on silica gel $(\mathrm{PE}: \mathrm{EA}=5: 1)$ affording DCM-Ac- $\beta$ GlcA as an orange solid. ${ }^{1} \mathrm{H}$ nuclear magnetic resonance (NMR) $\left(400 \mathrm{MHz}, \mathrm{CDCl}_{3}\right): \delta 8.88(\mathrm{~d}, J=8.3 \mathrm{~Hz}$, $1 \mathrm{H}), 7.74(\mathrm{t}, J=7.7 \mathrm{~Hz}, 1 \mathrm{H}), 7.56(\mathrm{~m}, 4 \mathrm{H}), 7.44(\mathrm{t}, J=7.7 \mathrm{~Hz}$, $1 \mathrm{H}), 7.05(\mathrm{~d}, J=8.5 \mathrm{~Hz}, 2 \mathrm{H}), 6.82(\mathrm{~s}, 1 \mathrm{H}), 6.70(\mathrm{~d}, J=15.9 \mathrm{~Hz}$, $1 \mathrm{H}), 5.46-5.22(\mathrm{~m}, 4 \mathrm{H}), 4.28(\mathrm{dd}, J=9.3,5.5 \mathrm{~Hz}, 1 \mathrm{H}), 3.74(\mathrm{~s}$, $3 \mathrm{H}), 2.08(\mathrm{~s}, 3 \mathrm{H}), 2.07(\mathrm{~s}, 6 \mathrm{H}) .{ }^{13} \mathrm{C} \mathrm{NMR}\left(101 \mathrm{MHz}, \mathrm{CDCl}_{3}\right): \delta$ $170.06,169.37,169.23,166.83,158.20,157.49,152.79,152.28$, $137.97,134.69,129.94,129.56,125.98,125.77,118.61,117.78$, $117.72,117.38,116.79,115.73,106.66,98.42,72.67,71.69,71.00$, 70.55, 68.97, 53.05, 20.63, 20.53 .

$\mathrm{MeONa}$ ( $3 \mathrm{mg}, 0.055 \mathrm{mmol}, 0.5$ equiv) was added to a solution of DCM-Ac- $\beta$ GlcA ( $67 \mathrm{mg}, 0.11 \mathrm{mmol}, 1$ equiv) in DCM and $\mathrm{MeOH}(12 \mathrm{~mL}, v / v=1: 2)$. The mixture was stirred for $5 \mathrm{~h}$ at room temperature and monitored by TLC (EA:MeOH: $\mathrm{H}_{2} \mathrm{O}=$ 4:1:0.3). Upon completion, the reaction mixture was evaporated under reduced pressure. The orange residue was purified by

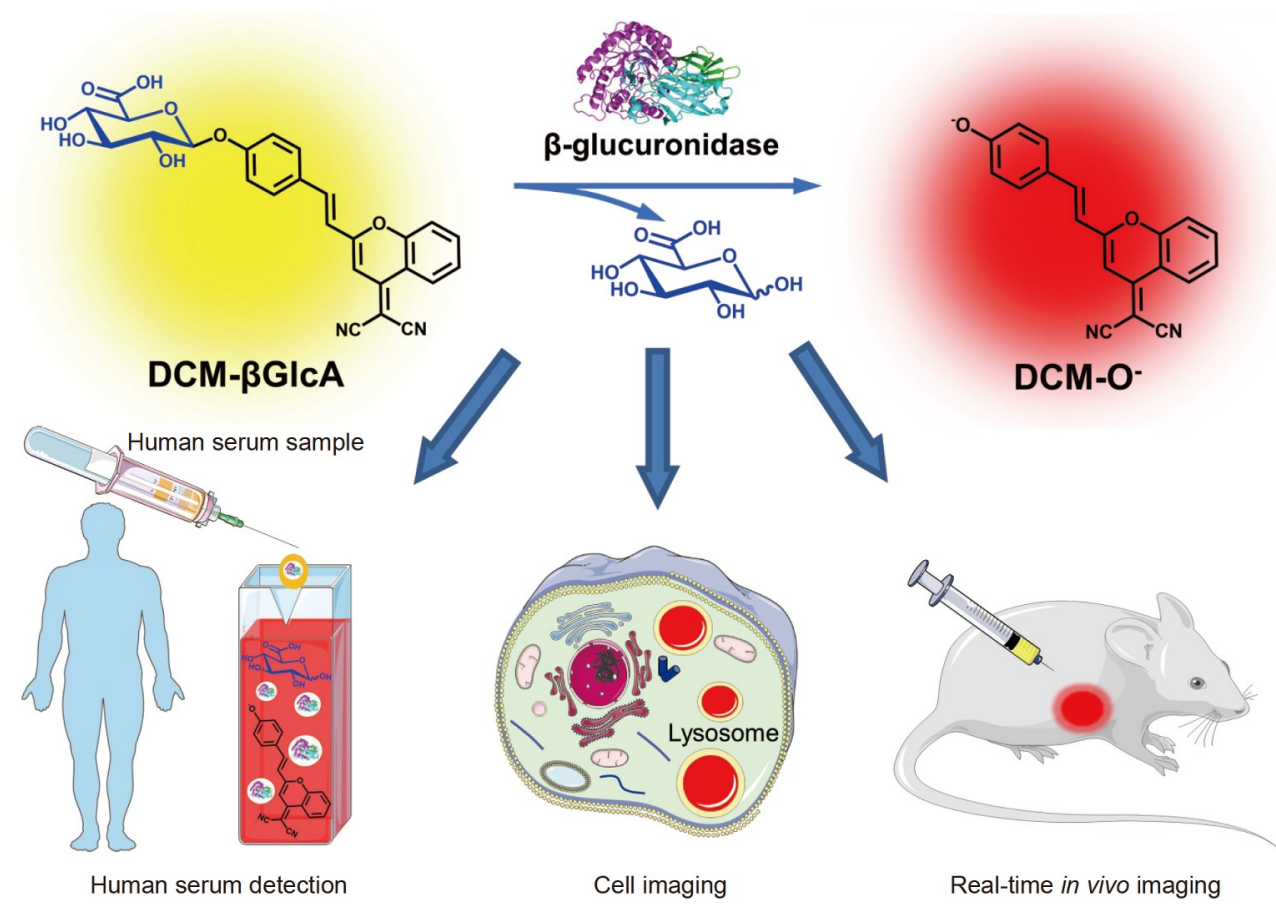

Scheme 1 Schematic illustration of the proposed sensing mechanism for GUS enzymatic activation of DCM- $\beta$ GlcA, and its specific detection and bioimaging of GUS activities in human serum, living cells and tumor-bearing nude mice. 


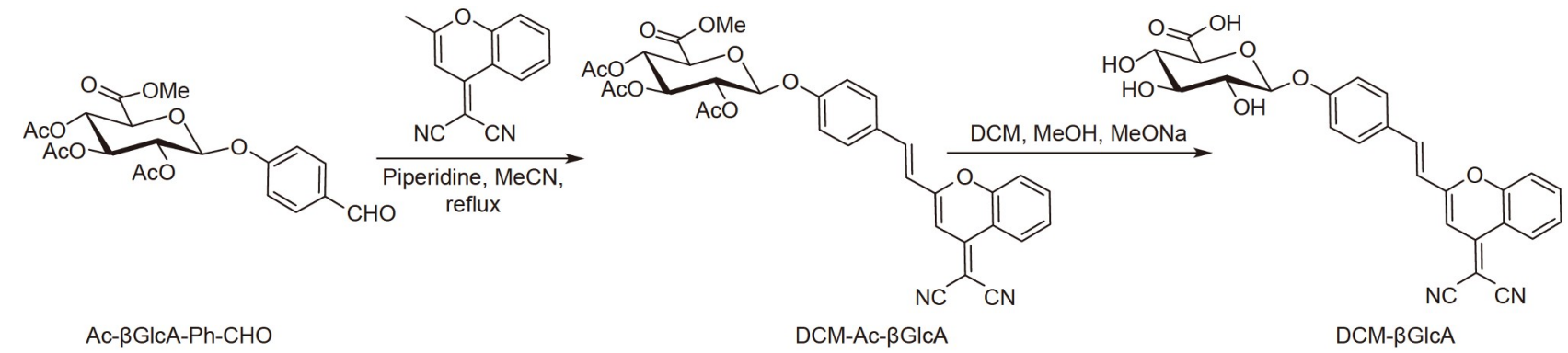

Scheme 2 Synthetic route of DCM- $\beta$ GlcA.

column chromatography on silica gel (EA:MeOH: $\mathrm{H}_{2} \mathrm{O}=4: 1: 0.1$ ) affording the target product DCM- $\beta$ GlcA as an orange solid. ${ }^{1} \mathrm{H}$ NMR $(400 \mathrm{MHz}$, dimethyl sulfoxide (DMSO)): $\delta 8.70(\mathrm{~d}, J=$ $8.0 \mathrm{~Hz}, 1 \mathrm{H}), 7.90(\mathrm{~d}, J=7.3 \mathrm{~Hz}, 1 \mathrm{H}), 7.84-7.64(\mathrm{~m}, 4 \mathrm{H}), 7.64-$ $7.52(\mathrm{~m}, 1 \mathrm{H}), 7.36(\mathrm{~d}, J=15.6 \mathrm{~Hz}, 1 \mathrm{H}), 7.11(\mathrm{~d}, J=7.5 \mathrm{~Hz}, 2 \mathrm{H})$, $6.95(\mathrm{~s}, 1 \mathrm{H}), 5.40(\mathrm{~s}, 1 \mathrm{H}), 5.20(\mathrm{~s}, 1 \mathrm{H}), 5.02(\mathrm{~d}, J=5.9 \mathrm{~Hz}, 1 \mathrm{H})$, $3.61(\mathrm{~s}, 1 \mathrm{H}), 3.27(\mathrm{~s}, 1 \mathrm{H}) \cdot{ }^{13} \mathrm{C}$ NMR (101 MHz, DMSO): $\delta 159.71$, $158.98,153.34,152.46,139.02,135.84,130.31,125.05,119.52$, $117.53,117.16,116.40,106.63,100.13,76.93,74.57,73.51,72.44$, 60.09. High-resolution mass spectrometry (HRMS): $[\mathrm{M}+\mathrm{H}]^{+}$ $\mathrm{m} / z 489.1290$ (calcd for $\mathrm{C}_{26} \mathrm{H}_{21} \mathrm{~N}_{2} \mathrm{O}_{8} 489.1298$ ).

\section{GUS activity assay in human serum samples}

The study was approved by the Ethics Committee of Shanxi Medical University, and informed consent was obtained either from the patient or from the patient's next of kin. Serum samples including five cancer samples and five healthy samples were collected from People's Hospital Affiliated to Shanxi Medical University (Taiyuan, China) and stored at $-80^{\circ} \mathrm{C}$ before use. A total of $10 \mu \mathrm{L}$ of serum was added to replace the GUS solution, and fluorescence intensity was measured by excitation at $530 \mathrm{~nm}$ and emission at $680 \mathrm{~nm}$. Detection of GUS using the enzymelinked immunosorbent assay (ELISA) Kit assay (Invitrogen, Carlsbad, CA, USA) was carried out in accordance with the manufacturer's instructions.

\section{Cellular fluorescence imaging}

HepG2 cells, NIH 3T3 cells, and human umbilical vein endothelial cells (HUVECs) were seeded and cultured in confocal imaging chambers. Subsequently, the cells were washed three times with $1 \times$ phosphate buffered saline (PBS) and incubated with or without $100 \mu \mathrm{mol} \mathrm{L}^{-1}$ baicalin (prepared in serum-free medium) for $30 \mathrm{~min}$ at $37^{\circ} \mathrm{C}$. Next, the cells were treated with DCM- $\beta$ GlcA $\left(50 \mu \mathrm{mol} \mathrm{L}^{-1}\right)$ in serum-free cell culture medium at $37^{\circ} \mathrm{C}$ for $30 \mathrm{~min}$. After being washed three times with PBS, the cells were imaged using a laser scanning confocal microscope (Olympus, Tokyo, Japan).

\section{Fluorescence imaging of GUS in tumor-bearing mice}

All animal studies were performed in compliance with the guidelines set by Tianjin Committee of Use and Care of Laboratory Animals and the overall project protocols were approved by the Animal Ethics Committee of Nankai University. Eight-week-old BALB/c mice were obtained from Beijing Vital River Laboratory Animal Technology Co. Ltd. (Beijing, China). To establish the xenograft HepG2 tumor-bearing mouse model, HepG2 cancer cells $\left(3 \times 10^{6}\right)$ suspended in $50 \mu \mathrm{L}$ of Dulbecco's modified Eagle medium (DMEM) were injected subcutaneously into the right axillae space of the mouse. When the tumor volumes reached approximately $160 \mathrm{~mm}^{3}$, the mice were used for in vivo imaging. DCM- $\beta$ GlcA $\left(0.075 \mathrm{mg} \mathrm{kg}^{-1}\right)$ was injected into the HepG2 tumor or intravenously injected in tumorbearing nude mice. Normal nude mice were used as controls and received intravenous injection of DCM- $\beta$ GlcA. Fluorescence imaging of cancer tissues in tumor-bearing mice was performed using an IVIS imaging system (Xenogen, Alameda, CA, USA). For the in vivo imaging, $\lambda_{\mathrm{ex}}=530 \pm 10 \mathrm{~nm}$ and $\lambda_{\mathrm{em}}=700 \pm$ $15 \mathrm{~nm}$.

\section{RESULTS AND DISCUSSION}

Design, synthesis, and spectroscopic properties of DCM- $\beta$ GIcA To generate an ultra-sensitive fluorescence assay capable of in vitro detection and in vivo optical imaging of GUS, DCM derivatives have been previously used as fluorogenic reporters because of their controllable emission in the NIR region, excellent intramolecular charge transfer (ICT), large Stokes shift $(>150 \mathrm{~nm})$, and good photostability [34,35]. In particular, the donor- $\pi$-acceptor $(D-\pi-A)$ characteristics of DCM are beneficial to probe design, and the electron-donating capability can be regulated by the phenolic group [32]. Following substituted group removal, a marked change of emission wavelength could be observed. For example, this substituted group could be cleaved by a target enzyme, as shown in Scheme 1. Based on the above features, a glucuronidase-activatable unit was covalently linked onto the DCM-OH moiety to synthesize a highly selective fluorescent probe for GUS detection. The DCM- $\beta$ GlcA exhibited a $63 \%$ yield under mild conditions, and the intermediate products as well as the probe were characterized by ${ }^{1} \mathrm{H}$ and ${ }^{13} \mathrm{C}$ NMR and HRMS (Figs S1-S7).

Next, we measured the change in spectroscopic properties of DCM- $\beta$ GlcA following incubation with GUS to examine its validity. DCM- $\beta$ GlcA exhibited a broad absorption pattern with a peak at $440 \mathrm{~nm}$ (Fig. 1a), with a quantum yield of 0.097. After reacting with GUS, this absorption peak at $440 \mathrm{~nm}$ decreased, and an accompanied new absorption peak at approximately $530 \mathrm{~nm}$ was observed, which was consistent with the absorption of $\mathrm{DCM}^{-} \mathrm{O}^{-}$. Following excitation at $440 \mathrm{~nm}$, a significant increase was observed in a broad emission band at $550-780 \mathrm{~nm}$, which exhibited a time- and concentration-dependence upon addition of GUS (Fig. 1b and Fig. S8a). Notably, previously reported DCM-based probes have been applied for ratiometric fluorescence detection of enzymes, and exhibited high sensitivity and accuracy $[32,36]$. In this work, upon $440-\mathrm{nm}$ excitation, an obvious ratiometric fluorescent signal could not be observed (Fig. $1 \mathrm{~b}$ and Fig. S8a). This was probably caused by the presence 

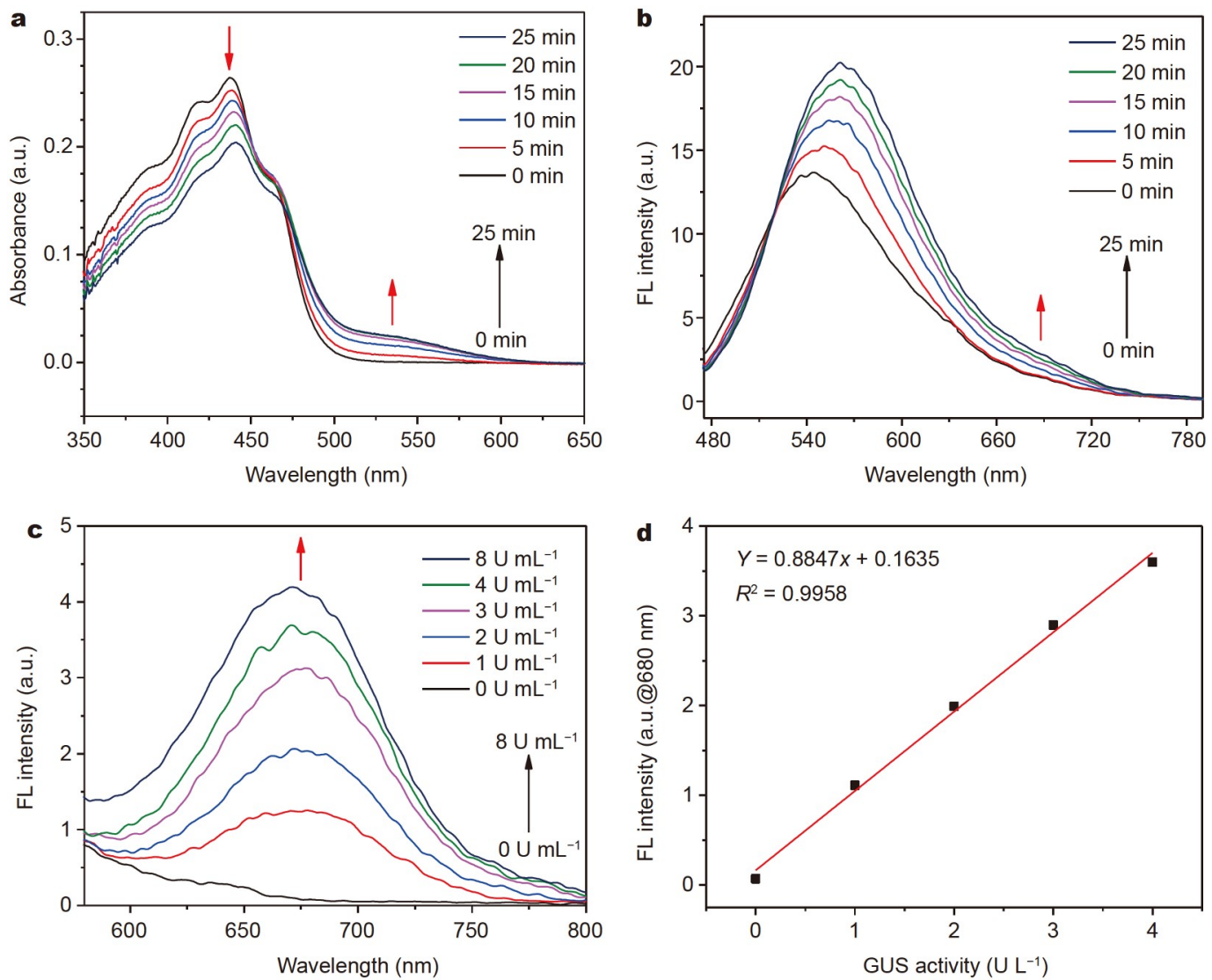

Figure 1 Spectroscopic properties of DCM- $\beta$ GlcA $\left(10 \mu \mathrm{mol} \mathrm{L}^{-1}\right)$ before and after reaction with GUS in a PBS buffer $\left(0.1 \mathrm{~mol} \mathrm{~L}^{-1}\right.$, pH $\left.7.4,30 \% \mathrm{DMSO}\right)$ : (a) time dependence of absorption spectra $(0-25 \mathrm{~min})$; (b) time dependence of fluorescence (FL) spectra $(0-25 \mathrm{~min}), \lambda_{\text {ex }}=440 \mathrm{~nm}$; (c) photoluminescence (PL) spectra of DCM- $\beta$ GlcA in the presence of GUS $\left(0-8 \mathrm{U} \mathrm{mL}^{-1}\right), \lambda_{\mathrm{ex}}=530 \mathrm{~nm}$; (d) linear relationship of DCM- $\beta \mathrm{GlcA}$ upon addition of increasing concentrations of GUS $\left(0-4 \mathrm{U} \mathrm{L}^{-1}\right)$ for $30 \mathrm{~min}$.

of GUS.

Just as predicted, after reacting with GUS, a significant NIR fluorescence enhancement with a peak at $680 \mathrm{~nm}$ appeared after excitation of the new absorption peak at $530 \mathrm{~nm}$. Thus, DCM$\beta$ GlcA also exhibited a large Stokes shift $(150 \mathrm{~nm})$, which was superior to previously reported NIR fluorescent probe used for GUS detection, as far as we knew. Importantly, the large Stokes shift could minimize background fluorescence and increase the signal to noise ratio, consequently reducing measurement error $[37,38]$. The GUS-induced fluorescence intensity was enhanced with increased GUS amount (Fig. 1c) and incubation duration (Fig. S8b). The variation of fluorescence signal was approximately 40 -fold higher than that at the initial state (Fig. 1c). The fluorescence intensity at $680 \mathrm{~nm}$ was linearly associated with GUS concentrations ranging between 0 and $4 \mathrm{U} \mathrm{L}^{-1}$ (Fig. 1d). The regression equation is $Y=0.8847 x+0.1635\left(R^{2}=0.9958\right)$, and the detection limit for GUS was $0.19 \mathrm{U} \mathrm{L}^{-1}$ based on the $3 \sigma / k$ method, indicating that DCM- $\beta$ GlcA was sensitive enough and could be used for GUS detection in biological samples. Furthermore, DCM- $\beta$ GlcA is one of the most sensitive fluorescent probes that have ever been used for GUS detection (Table S1). These results demonstrate that DCM- $\beta$ GlcA could serve as a light-up NIR fluorescence probe for rapid GUS detection with high sensitivity.

For imaging and sensing probes, photostability is an important feature for long-term in vivo imaging. The time-course fluorescence measurements were performed to evaluate the photostability of DCM- $\beta$ GlcA, while indocyanine green (ICG), an FDA-approved commercial NIR dye, was selected as a control. As shown in Fig. S9, negligible fluorescence intensity decrease was observed for DCM- $\beta$ GlcA after $8 \mathrm{~min}$ of light irradiation, indicating that this probe had high photostability, much better than that of ICG. In addition to high photostability, DCM- $\beta$ GlcA also had an excellent physiological stability in PBS at $37^{\circ} \mathrm{C}$ without any autohydrolysis, as revealed by unchanged escaping time by high performance liquid chromatography (HPLC) (Fig. S10). Moreover, pH value usually has an important effect on the photophysical properties of the imaging and sensing probes. Upon excitation at $530 \mathrm{~nm}$, the fluorescence intensity at $680 \mathrm{~nm}$ of DCM- $\beta$ GlcA showed no significant changes in the $\mathrm{pH}$ range of 3.0-10.0 (Fig. S11). In particular, the hydrolytic product of DCM- $\beta$ GlcA showed high fluorescence intensity over a $\mathrm{pH}$ range of 7.0-7.5, indicating this probe could be applied for light-up measurement of GUS at physiological $\mathrm{pH}$.

\section{Sensing mechanism}

To gain insight into the sensing mechanism of DCM- $\beta$ GlcA, the final products generated following incubation with GUS were characterized using HPLC analysis and electrospray ionization mass spectra (ESI-MS). HPLC profiles corroborated that DCM$\beta$ GlcA was capable of being cleaved by GUS to generate DCM$\mathrm{O}^{-}$, which gradually increased with prolonged activation time (Fig. 2a). In the ESI-MS spectra of DCM- $\beta$ GlcA reacted with 

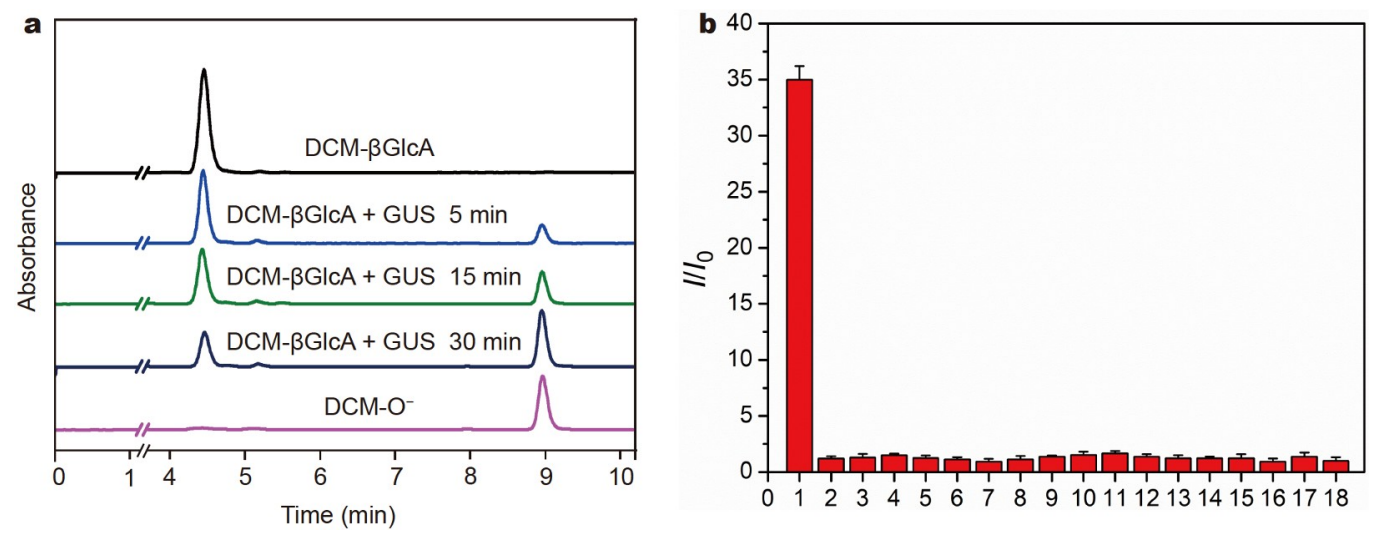

Figure 2 (a) HPLC chromatograms of DCM-O- and DCM- $\beta$ GlcA before and at various time points after reaction with GUS; (b) fluorescence responses of DCM- $\beta$ GlcA $\left(10 \mu \mathrm{mol} \mathrm{L}^{-1}\right)$ toward different kinds of enzymes and analytes at $37^{\circ} \mathrm{C}$ for $30 \mathrm{~min}$. Legends: (1) GUS; (2) $\alpha$-Glc; (3) $\beta$-Gal; (4) ALP; (5) $\alpha$-AMY; (6) $\beta$-NAG; (7) Ly; (8) $\beta$-Glc; (9) $\mathrm{Ca}^{2+}$; (10) $\mathrm{Zn}^{2+}$; (11) $\mathrm{Mg}^{2+}$; (12) $\mathrm{Mn}^{2+}$; (13) $\mathrm{Fe}^{2+}$; (14) $\mathrm{Fe}^{3+}$; (15) bovine serum albumin; (16) glutathione; (17) $\mathrm{H}_{2} \mathrm{O}_{2}$; (18) blank.

GUS, the peak of hydrolysis product was clearly observed at 311.0817 (Fig. S12), which was in accordance with that of DCM$\mathrm{O}^{-}$in a previous report [32]. These results indicate that GUS could catalyze the hydrolysis of DCM- $\beta$ GlcA via cleavage of carbon-oxygen bond. This reaction was followed by the release of an electron-rich aglycon, DCM-O ${ }^{-}$, which emitted red fluorescence in the NIR region with a large spectral shift.

To validate whether DCM- $\beta$ GlcA could be used in complex biological systems, we further examined its selectivity toward the various hydrolases and analytes. These enzymes included $\alpha$ glucosidase $(\alpha-G l c), \beta$-galactosidase $(\beta-G a l)$, alkaline phosphatase (ALP), $\alpha$-amylase ( $\alpha$-AMY), $\beta$ - $N$-acetyl glucosaminidase ( $\beta$ NAG), lysozyme (Ly), and $\beta$-Glc. The analytes involved in this experiment were endogenous substances, including metal ions, serum proteins, oxidative and reductive species. A significant fluorescence enhancement of DCM- $\beta$ GlcA $\left(10 \mu \mathrm{mol} \mathrm{L}^{-1}\right)$ following the addition of GUS $\left(50 \mu \mathrm{g} \mathrm{m}^{-1}\right)$ was observed (Fig. $2 \mathrm{~b}$ ), while little fluorescence changes were observed upon addition of other hydrolase or analytes. These observations demonstrate the superior selectivity of DCM- $\beta$ GlcA toward GUS over other competitive analyte species. Thus, this probe could allow for the accurate detection of GUS in complex biological environments.

\section{Detection of GUS in human serum samples}

Serum GUS levels can serve as biomarkers for cancer diagnosis [39]. In addition, abnormal serum GUS levels are associated with several diseases, including epilepsy [40], diabetes mellitus [41] and liver disease $[42,43]$. To evaluate the potential application and detection accuracy in a clinical setting, we used the DCM$\beta$ GlcA probe to detect GUS in human serum of both healthy people and cancer patients and compared the results with those obtained using a commercially available GUS ELISA kit. Serum results obtained using DCM- $\beta$ GlcA showed that the GUS levels in cancer patients $\left(14.06 \pm 1.68 \mathrm{U} \mathrm{L}^{-1}\right)$ were significantly higher than those in healthy people $\left(6.69 \pm 1.07 \mathrm{U} \mathrm{L}^{-1}\right)$ (Fig. 3), suggesting that serum GUS levels were associated with cancer and could serve as a cancer biomarker. The GUS recovery from serum samples was over $97 \%$ using DCM- $\beta$ GlcA, indicating that the serum detection for our probe had good accuracy (Table S2). In addition, the measured results using our probe were similar to those obtained using the ELISA kit (Fig. 3). The correlation analysis showed a high correlation coefficient $(0.9910)$ between the results obtained using the two methods, indicating that the

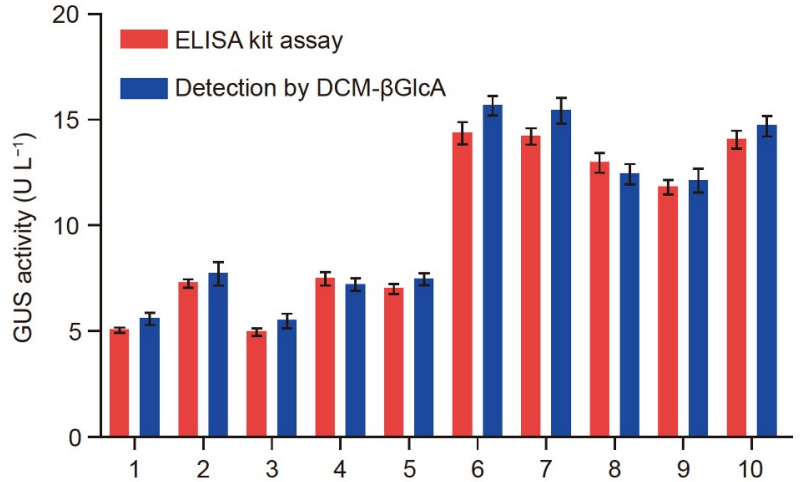

Figure 3 Endogenous GUS detection in human serum samples by using DCM- $\beta$ GlcA or GUS ELISA kit assay. 1-5 represent serum samples from healthy individuals, and 6-10 represent serum samples from cancer patients.

methods had satisfactory consistency (Fig. S13). However, the sensing method reported herein is more convenient, easy to operate, and can be performed more quickly than ELISA. Taken together, our results illustrate the great potential of DCM- $\beta$ GlcA as an efficient diagnostic reagent for GUS detection.

\section{Fluorescence imaging of endogenous GUS in living cells}

Next, to test whether DCM- $\beta$ GlcA could realize the fluorescence imaging of endogenous GUS activity in living cells, we chose human hepatocellular carcinoma HepG2 cells as the experimental cell line for our study, because HepG2 cells exhibit a high GUS expression and have been widely used to investigate lysosomal enzymes [44]. NIH-3T3 cells and HUVECs were used as control cells because of their low GUS expression $[45,46]$. The CCK8 cytotoxicity assay results showed that DCM- $\beta$ GlcA had no cytotoxicity to any of the three cell types even at high concentrations (up to $100 \mu \mathrm{mol} \mathrm{L}^{-1}$ ), indicating that this probe could be applied to live cell imaging (Fig. S14). Following incubation with DCM- $\beta$ GlcA $\left(50 \mu \mathrm{mol} \mathrm{L}^{-1}\right)$ at $37^{\circ} \mathrm{C}$ for $60 \mathrm{~min}$, the fluorescence intensity in the red channel $(650-710 \mathrm{~nm})$ was observed in these three cell types, which suggested that this probe could be easily internalized by cells (Fig. 4a). Moreover, the fluorescence intensity obtained in the NIR region in HepG2 cells was significantly higher than that in NIH-3T3 cells and HUVECs (Fig. 4a). Baicalin, a GUS inhibitor [47], was further selected to evaluate the specificity of DCM- $\beta$ GlcA toward GUS. As shown 


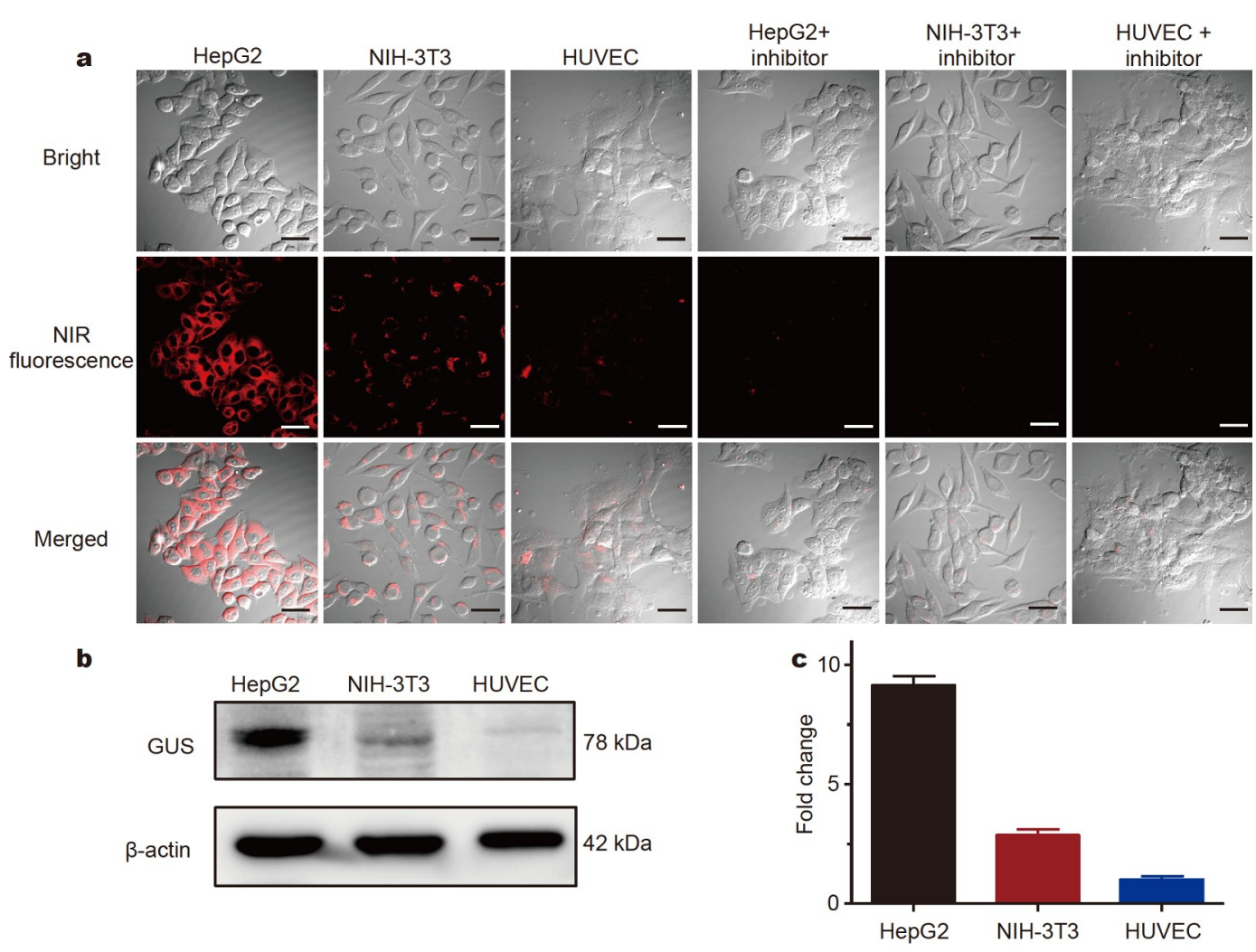

Figure 4 (a) Confocal laser scanning microscopy (CLSM) images of non-pretreated or inhibitor-pretreated HepG2 cells, NIH-3T3 cells or HUVECs after incubation with DCM- $\beta$ GlcA $\left(50 \mu \mathrm{mol} \mathrm{L}^{-1}\right)$ at $37^{\circ} \mathrm{C}$ for $60 \mathrm{~min}$. NIR fluorescence images obtained in $650-710 \mathrm{~nm}, \lambda_{\mathrm{ex}}=559 \mathrm{~nm}$. Scale bar: $20 \mu \mathrm{m}$. (b) Western blot assay for the expression of GUS in HepG2 cells, NIH 3T3 cells or HUVECs. (c) Quantification of western blot assay for fold change in expression of GUS.

in Fig. 4a, baicalin pretreatment leads to negligible NIR fluorescence signals inside these cells, as GUS activity is largely inhibited by baicalin. Such results confirm that the light-up fluorescence signal was derived from the catalytic effect of GUS on DCM- $\beta$ GlcA. The imaging results were consistent with the western blot results for GUS in these three cell types, demonstrating the high sensitivity of DCM- $\beta$ GlcA for GUS detection (Fig. $4 \mathrm{~b}, \mathrm{c}$ ). These results confirmed that DCM- $\beta$ GlcA could monitor endogenous GUS activity in living cells with high sensitivity, and could therefore be used to distinguish GUSoverexpressing cancer cells from normal cells.

\section{In vivo imaging of GUS activity in tumors}

NIR imaging is a rapid and noninvasive detection technology characterized by high sensitivity, deep tissue penetration, easy operation and low cost [48]. Until now, only few fluorescent probes have been reported to be useful for in vivo imaging of GUS activity in mice [20,21]. Based on the performance of our DCM- $\beta$ GlcA probe, we further investigated whether it could be used for real-time in vivo imaging of GUS activity using an invivo imaging system. The in vivo tumor imaging ability of DCM$\beta$ GlcA was verified through the GUS-overexpressing xenograft HepG2 tumor-bearing mouse model, which was generated using subcutaneous injection of HepG2 cells into one flank of the nude mouse. After intravenous injection of DCM- $\beta$ GlcA for $2 \mathrm{~h}$, NIR fluorescent signals were captured in the tumor site and intestines, which was due to the generation of DCM-O $\mathrm{O}^{-}$from DCM$\beta$ GlcA hydrolyzed by GUS (Fig. S15). The strong fluorescence in intestines shall be caused by the presence of intestine bacteria which also produces the large amounts of GUS in intestine [49]. In addition, almost no fluorescence was seen in the heart, lung, liver, spleen, kidney, and other organs, which suggested that high GUS specificity of our DCM- $\beta$ GlcA in whole body imaging.

To improve the visualization of GUS activity in tumor, we further used intratumoral injection of DCM- $\beta$ GlcA to amplify the fluorescent signal. As shown in Fig. 5a, we can see an obvious NIR fluorescence signal at the tumor site following in situ injection of DCM- $\beta$ GlcA $\left(0.075 \mathrm{mg} \mathrm{kg}^{-1}\right)$. In comparison, there was minimal light-up fluorescence following subcutaneous injection of DCM- $\beta$ GlcA in the contralateral flanks of nude mice (Fig. 5a). Additionally, we further proved that the NIR fluorescence originated from the activation of DCM- $\beta$ GlcA in the tumor by the ex vivo imaging of major organs and tumor collected at $2 \mathrm{~h}$ post-injection, which showed that only the tumor yielded fluorescent signal (Fig. 5b). Moreover, this strong fluorescent signal lasted for at least $2 \mathrm{~h}$, which might provide some convenience for cancer diagnosis and treatment.

In light of the abovementioned results, we further investigated whether DCM- $\beta$ GlcA could be used for GUS bioactivity imaging in normal tissue and tumor tissue, which is important for cancer diagnosis. Tumor tissues were obtained from the xenograft HepG2 tumor-bearing mice, and cut into $10-\mu \mathrm{m}$ sections using a freezing microtome for DCM- $\beta$ GlcA and GUS immunofluorescent staining. As displayed in Fig. $5 c$, intense fluorescence signal generated from the DCM- $\beta$ GlcA (red fluorescence) was consistent with the immunofluorescent results of the GUS antibody (green fluorescence). Taken together, these findings suggest that the DCM- $\beta$ GlcA probe represents a feasible and 
a

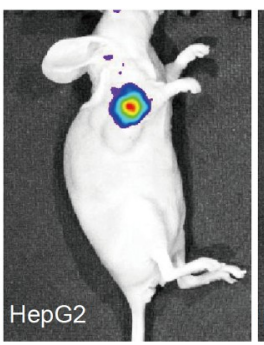

$D C M-\beta G \mid c A$
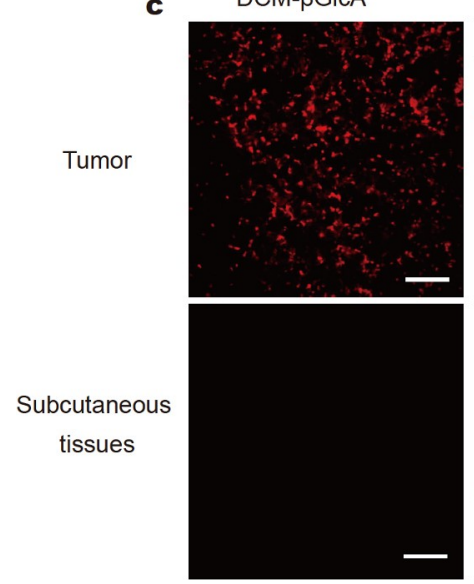

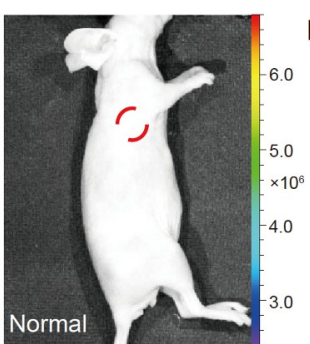

Immunofluorescence
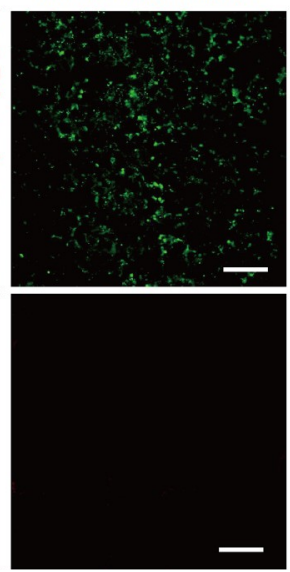

b

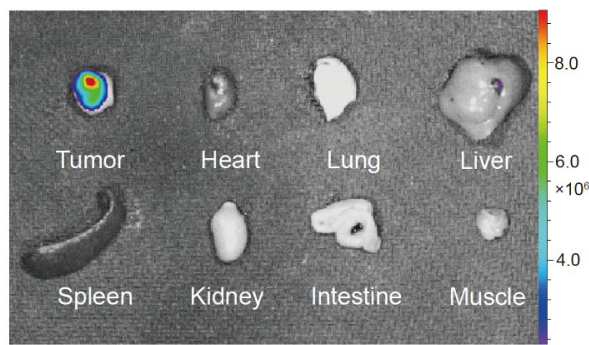

DAPI
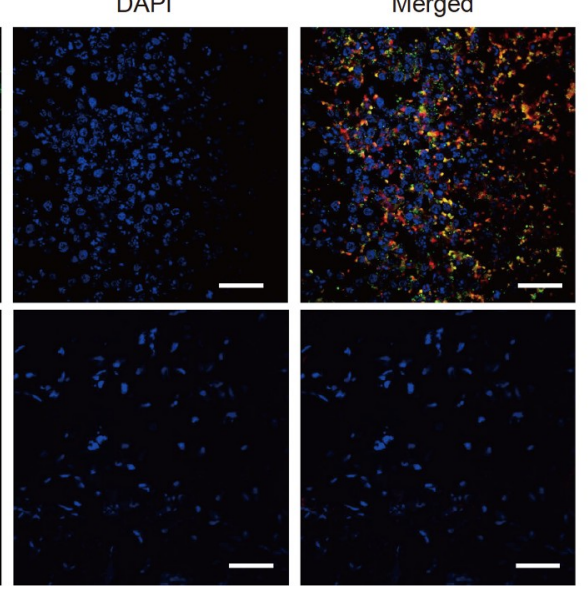

Figure 5 (a) In vivo imaging of GUS activity in tumor (HepG2)-bearing nude mice $2 \mathrm{~h}$ after tumor injection of $\mathrm{DCM}-\beta \mathrm{GlcA}\left(0.075 \mathrm{mg} \mathrm{kg}^{-1}\right.$ ), and subcutaneous injection at corresponding contralateral area served as control. (b) Fluorescence images of the main internal organs after anatomy. (c) Fluorescence microscopy images of DCM- $\beta$ GlcA for the tissue slices of HepG2 tumor tissues and normal tissues (subcutaneous tissues), respectively. Scale bar: $100 \mu \mathrm{m}$.

convenient tool for detecting and imaging GUS activity in patients' serums, cells, tissue sections, and whole body. GUS is abundantly expressed in the vast majority of solid tumors, but its expression level is relatively low at early stages of tumor development [50]. Thus the NIR probe DCM- $\beta$ GlcA with a very low limit of detection has the potential to be applied in the tumor grading due to its capability of monitoring GUS activity in vivo. Since high level of GUS can be found in most solid tumors, it has become an attractive target for the development of antitumor drugs [51]. However, the expression and activity of GUS vary among different kinds of tumors. It is also possible that DCM$\beta$ GlcA could be used to assess the enzyme activity of GUS in a certain kind of tumor for predicting the efficacy of chemotherapy based-on GUS-responsive antitumor drugs. Furthermore, the capability of DCM- $\beta$ GlcA to show sensitive detection of GUS in patients' serums through the fluorescence light-up approach also makes it a much easier, faster and more facile method than ELISA for potential clinical practices.

\section{CONCLUSIONS}

In summary, we presented an NIR fluorescent probe (DCM$\beta \mathrm{GlcA}$ ) with large Stokes shift for GUS detection, which consisted of DCM as an NIR fluorophore and a glucuronic acid residue as the GUS-active trigger. DCM- $\beta$ GlcA displayed lightup NIR fluorescent signals in response to GUS with high sensitivity. This probe could detect GUS activity in human serum samples from both healthy individuals and cancer patients, the results of which were consistent with those of ELISA. Furthermore, the results from in vitro experiments demonstrate that DCM- $\beta$ GlcA could enable fluorescent visualization of GUS activity in living cells without cytotoxicity. Importantly, DCM$\beta \mathrm{GlcA}$ was also successfully used as a real-time imaging probe for endogenous GUS in tumor-bearing mouse models. Based on the above results, DCM- $\beta$ GlcA could be regarded as a promising and easy tool for tracking GUS activity in vitro, in vivo, and ex vivo, which can greatly benefit cancer diagnosis and imagingguided treatment.

Received 4 June 2021; accepted 23 August 2021; published online 30 September 2021

1 El-Naggar M, Almahli $\mathrm{H}$, Ibrahim HS, et al. Pyridine-ureas as potential anticancer agents: Synthesis and in vitro biological evaluation. Molecules, 2018, 23: 1459

2 Wu L, Qu X. Cancer biomarker detection: Recent achievements and challenges. Chem Soc Rev, 2015, 44: 2963-2997

3 Chojnowska S, Kępka A, Szajda SD, et al. Exoglycosidase markers of diseases. Biochem Soc Trans, 2011, 39: 406-409

4 Iozzo RV. Proteoglycans and neoplastic-Mesenchymal cell interactions. Hum Pathol, 1984, 15: 2-10

5 Kim DH, Shim SB, Kim NJ, et al. Beta-glucuronidase-inhibitory activity and hepatoprotective effect of ganoderma lucidum. Biol Pharmaceut Bull, 1999, 22: 162-164

6 Finch PJ, Ryan FP, Rogers K, et al. Gastric enzymes as a screening test for gastric cancer. Gut, 1987, 28: 319-322

7 Anouar EH, Moustapha ME, Taha M, et al. Synthesis, molecular docking and $\beta$-glucuronidase inhibitory potential of indole base oxadiazole derivatives. Molecules, 2019, 24: 963

8 Sperker B, Werner U, Mürdter TE, et al. Expression and function of $\beta$ glucuronidase in pancreatic cancer: Potential role in drug targeting. Naunyn-Schmiedebergs Arch Pharmacol, 2000, 362: 110-115

9 Tranoy-Opalinski I, Legigan T, Barat R, et al. $\beta$-Glucuronidase-responsive prodrugs for selective cancer chemotherapy: An update. Eur J 
Med Chem, 2014, 74: 302-313

10 Sperker B, Backman JT, Kroemer HK. The role of $\beta$-glucuronidase in drug disposition and drug targeting in humans. Clin Pharmacokinet, 1997, 33: 18-31

11 Waszkiewicz N, Szajda SD, Konarzewska-Duchnowska E, et al. Serum $\beta$-glucuronidase as a potential colon cancer marker: A preliminary study. Postepy Hig Med Dosw, 2015, 69: 436-439

12 Fernández-Cuervo G, Tucker KA, Malm SW, et al. Diamagnetic imaging agents with a modular chemical design for quantitative detection of $\beta$-galactosidase and $\beta$-glucuronidase activities with CatalyCEST MRI. Bioconjugate Chem, 2016, 27: 2549-2557

13 Su YC, Cheng TC, Leu YL, et al. PET imaging of $\beta$-glucuronidase activity by an activity-based ${ }^{124} \mathrm{I}$-trapping probe for the personalized glucuronide prodrug targeted therapy. Mol Cancer Ther, 2014, 13: 2852-2863

14 Marciniak J, Zalewska A, Popko J, et al. Optimization of an enzymatic method for the determination of lysosomal $N$-acetyl- $\beta$ - $D$-hexosaminidase and $\beta$-glucuronidase in synovial fluid. Clin Chem Lab Med, 2006, 44: 933-937

15 Lu S, Li G, Lv Z, et al. Facile and ultrasensitive fluorescence sensor platform for tumor invasive biomaker $\beta$-glucuronidase detection and inhibitor evaluation with carbon quantum dots based on inner-filter effect. Biosens Bioelectron, 2016, 85: 358-362

16 Gong P, Sun L, Wang F, et al. Highly fluorescent N-doped carbon dots with two-photon emission for ultrasensitive detection of tumor marker and visual monitor anticancer drug loading and delivery. Chem Eng J, 2019, 356: 994-1002

17 Guo L, Liu Y, Kong R, et al. Turn-on fluorescence detection of $\beta$ glucuronidase using RhB@MOF-5 as an ultrasensitive nanoprobe. Sens Actuat B-Chem, 2019, 295: 1-6

18 Huo X, Tian X, Li Y, et al. A highly selective ratiometric fluorescent probe for real-time imaging of $\beta$-glucuronidase in living cells and zebrafish. Sens Actuat B-Chem, 2018, 262: 508-515

19 Cheng TC, Roffler SR, Tzou SC, et al. An activity-based near-infrared glucuronide trapping probe for imaging $\beta$-glucuronidase expression in deep tissues. J Am Chem Soc, 2012, 134: 3103-3110

20 Jin $\mathrm{Y}$, Tian $\mathrm{X}$, Jin L, et al. Highly specific near-infrared fluorescent probe for the real-time detection of $\beta$-glucuronidase in various living cells and animals. Anal Chem, 2018, 90: 3276-3283

21 Feng L, Yang Y, Huo X, et al. Highly selective NIR probe for intestinal $\beta$-glucuronidase and high-throughput screening inhibitors to therapy intestinal damage. ACS Sens, 2018, 3: 1727-1734

22 Wei X, Hao M, Hu XX, et al. A near-infrared fluorescent probe with large stokes shift for accurate detection of $\beta$-glucuronidase in living cells and mouse models. Sens Actuat B-Chem, 2021, 326: 128849

23 Parashurama N, O'Sullivan TD, De La Zerda A, et al. Continuous sensing of tumor-targeted molecular probes with a vertical cavity surface emitting laser-based biosensor. J Biomed Opt, 2012, 17: 117004

24 Yin J, Kwon Y, Kim D, et al. Cyanine-based fluorescent probe for highly selective detection of glutathione in cell cultures and live mouse tissues. J Am Chem Soc, 2014, 136: 5351-5358

25 Zhao M, Wang J, Lei Z, et al. NIR-II pH sensor with a FRET adjustable transition point for in situ dynamic tumor microenvironment visualization. Angew Chem Int Ed, 2021, 60: 5091-5095

26 Yang Y, Wang S, Lu L, et al. NIR-II chemiluminescence molecular sensor for in vivo high-contrast inflammation imaging. Angew Chem Int Ed, 2020, 59: 18380-18385

27 Fan Y, Wang P, Lu Y, et al. Lifetime-engineered NIR-II nanoparticles unlock multiplexed in vivo imaging. Nat Nanotech, 2018, 13: 941-946

28 Zhong $\mathrm{Y}$, Ma $\mathrm{Z}$, Wang $\mathrm{F}$, et al. In vivo molecular imaging for immunotherapy using ultra-bright near-infrared-IIb rare-earth nanoparticles. Nat Biotechnol, 2019, 37: 1322-1331

29 Wu Y, Huang S, Wang J, et al. Activatable probes for diagnosing and positioning liver injury and metastatic tumors by multispectral optoacoustic tomography. Nat Commun, 2018, 9: 3983

30 Ghavamipour F, Rahmani H, Shanehsaz M, et al. Enhanced sensitivity of VEGF detection using catalase-mediated chemiluminescence immunoassay based on CdTe QD/ $\mathrm{H}_{2} \mathrm{O}_{2}$ system. J Nanobiotechnol, 2020, 18: 93
31 Chen S, Li H, Hou P. A large stokes shift fluorescent probe for sensing of thiophenols based on imidazo[1,5- $\alpha$ ]pyridine in both aqueous medium and living cells. Anal Chim Acta, 2017, 993: 63-70

$32 \mathrm{Gu} \mathrm{K}, \mathrm{Xu} \mathrm{Y}, \mathrm{Li} \mathrm{H}$, et al. Real-time tracking and in vivo visualization of $\beta$-galactosidase activity in colorectal tumor with a ratiometric nearinfrared fluorescent probe. J Am Chem Soc, 2016, 138: 5334-5340

33 Zhang P, Jiang XF, Nie X, et al. A two-photon fluorescent sensor revealing drug-induced liver injury via tracking $\gamma$-glutamyltranspeptidase (GGT) level in vivo. Biomaterials, 2016, 80: 46-56

$34 \mathrm{Wu} \mathrm{X}$, Sun $\mathrm{X}$, Guo Z, et al. In vivo and in situ tracking cancer chemotherapy by highly photostable NIR fluorescent theranostic prodrug. J Am Chem Soc, 2014, 136: 3579-3588

35 Li M, Wu X, Wang Y, et al. A near-infrared colorimetric fluorescent chemodosimeter for the detection of glutathione in living cells. Chem Commun, 2014, 50: 1751-1753

36 Li Q, Yan C, Zhang J, et al. Ratiometric and light-up near-infrared fluorescent $\mathrm{dcm}$-based probe for real-time monitoring endogenous tyrosinase activity. Dyes Pigments, 2019, 162: 802-807

37 Jiang M, Gu X, Lam JWY, et al. Two-photon AIE bio-probe with large stokes shift for specific imaging of lipid droplets. Chem Sci, 2017, 8 : 5440-5446

38 Hong J, Zhou E, Gong S, et al. A red to near-infrared fluorescent probe featuring a super large stokes shift for light-up detection of endogenous $\mathrm{H}_{2} \mathrm{~S}$. Dyes Pigments, 2019, 160: 787-793

39 Mürdter TE, Friedel G, Backman JT, et al. Dose optimization of a doxorubicin prodrug (HMR 1826) in isolated perfused human lungs: Low tumor $\mathrm{pH}$ promotes prodrug activation by $\beta$-glucuronidase. J Pharmacol Exp Ther, 2002, 301: 223-228

40 Falkenbach A, Wigand R, Unkelbach U, et al. Cyclosporin treatment in rheumatoid arthritis is associated with an increased serum activity of $\beta$ glucuronidase. Scandin J Rheumatol, 1993, 22: 83-85

41 Miller BF. Increase of serum $\beta$-glucuronidase activity in human diabetes mellitus. J Am Med Assoc, 1966, 195: 189-192

42 Pineda EP, Goldbarg JA, Banks BM, et al. The significance of serum $\beta$ glucuronidase activity in patients with liver disease. Gastroenterology, 1959, 36: 202-213

43 George J. Elevated serum $\beta$-glucuronidase reflects hepatic lysosomal fragility following toxic liver injury in rats. Biochem Cell Biol, 2008, 86: $235-243$

44 Sperker B, Tomkiewicz C, Burk O, et al. Regulation of human $\beta$-glucuronidase by A23187 and thapsigargin in the hepatoma cell line HepG2. Mol Pharmacol, 2001, 59: 177-182

45 Diment S, Dean MF. Receptor-mediated endocytosis of fibroblast $\beta$ glucuronidase by peritoneal macrophages. BioChim Biophys Acta (BBA) - Mol Cell Res, 1983, 762: 165-174

46 Shimoi K, Nakayama T. Glucuronidase deconjugation in inflammation. Methods Enzymol, 2005, 400: 263-272

47 Guan HY, Li PF, Wang XM, et al. Shengjiang Xiexin decoction alters pharmacokinetics of irinotecan by regulating metabolic enzymes and transporters: A multi-target therapy for alleviating the gastrointestinal toxicity. Front Pharmacol, 2017, 8: 769

48 Liu J, Chen C, Ji S, et al. Long wavelength excitable near-infrared fluorescent nanoparticles with aggregation-induced emission characteristics for image-guided tumor resection. Chem Sci, 2017, 8: 27822789

49 Chamseddine AN, Ducreux M, Armand JP, et al. Intestinal bacterial $\beta$ glucuronidase as a possible predictive biomarker of irinotecan-induced diarrhea severity. Pharmacol Ther, 2019, 199: 1-15

50 de Graaf M, Boven E, Scheeren HW, et al. Beta-glucuronidase-mediated drug release. Curr Pharm Des, 2002, 8: 1391-1403

51 Compain G, Oumata N, Clarhaut J, et al. A $\beta$-glucuronidase-responsive albumin-binding prodrug for potential selective kinase inhibitor-based cancer chemotherapy. Eur J Med Chem, 2018, 158: 1-6

Acknowledgements This work was supported by the National Natural Science Foundation of China (81801858), China Postdoctoral Science Foundation (2018M641676), and the Applied Basic Research Program of Shanxi Province (201801D221408). 
Author contributions Zhou X, Zhang G, Ding D and Feng G designed the study and wrote the manuscript; Zhou X and Zhang H supervised the project and analyzed the data; Gao Z and Zhang G carried out the synthesis; Hou J detected the enzyme activity in the human serum; Zhou X, Wang D and $\mathrm{He}$ $M$ performed the remaining experiments. All authors contributed to the general discussion.

Conflict of interest The authors declare that they have no conflict of interest.

Supplementary information Experimental details and supporting data are available in the online version of the paper.

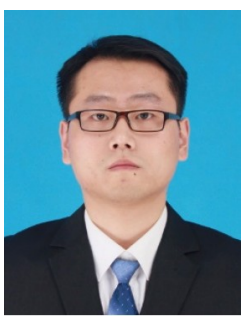

Xin Zhou received his $\mathrm{PhD}$ degree from the College of Life Sciences, Nankai University, in 2017. He is currently an associate professor at the College of Medical Imaging and Key Laboratory of Cellular Physiology, Ministry of Education, Shanxi Medical University. His current research focuses on the design and synthesis of nanomaterials for biomedical imaging and disease treatment.

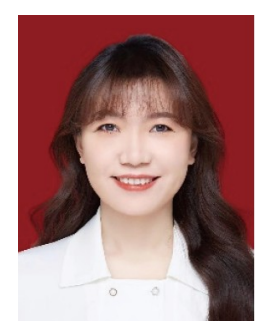

Deping Wang is a lecturer at the Department of Physiology and Key Laboratory of Cellular Physiology, Ministry of Education, Shanxi Medical University. She received her $\mathrm{PhD}$ degree from Tianjin University in 2017. Her research interests include the crystal structures of proteins and nanotoxicology.

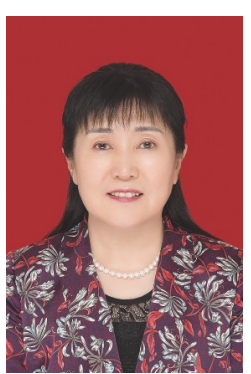

Hui Zhang is currently a vice president of Shanxi Medical University and director of the Department of Radiology, the First Hospital of Shanxi Medical University. She received her $\mathrm{PhD}$ degree (2002) from Shanghai Medical College of Fudan University, under the direction of Prof. Kangrong Zhou. Her research interests focus on the imaging diagnosis of central nervous system diseases, multimodal function magnetic resonance imaging, imaging genomics, and molecular imaging.

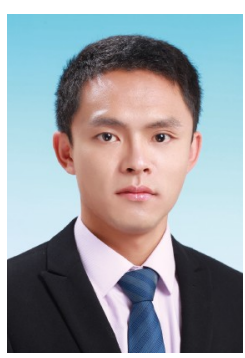

Guoqiang Zhang received his $\mathrm{PhD}$ degree from the College of Pharmacy, Nankai University in 2018. He is currently a postdoctoral fellow under the supervision of Prof. Dan Ding at the State Key Laboratory of Medicinal Chemical Biology, Nankai University. His current research focuses on the design and synthesis of smart/functional molecular imaging probes and exploration of their biomedical applications.

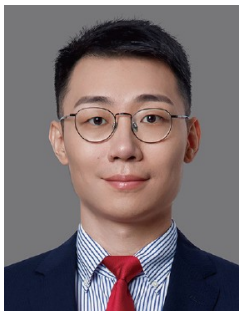

Guangxue Feng received his $\mathrm{PhD}$ degree from the Department of Chemical and Biomolecular Engineering, National University of Singapore in 2016. He is currently a professor at the State Key Laboratory of Luminescent Materials and Devices, South China University of Technology. His current research focuses on the design and synthesis of smart/functional optical nanomaterials for molecular imaging, phototheranostics and environment protection.

\section{用于血清、活细胞及小鼠荷瘤中 $\beta$-葡萄糖醛酸苷酶 检测成像的高灵敏点亮型近红外苂光探针}

\author{
周金金 ${ }^{1 \dagger}$, 王德平 ${ }^{1 \dagger}$, 高志远 ${ }^{2}$, 何明玥 ${ }^{1}$, 侯佳宜 ${ }^{1,3}$, 张辉 ${ }^{1^{*}}$, 张国强 ${ }^{*}$, \\ 丁 ( $^{2}$, 冯光雪 $4^{*}$
}

摘要 $\beta$-葡萄糖醛酸苷酶(GUS)在肿瘤的发生、转移和进展中具有关 键作用, 因而成为一种很有应用前景的癌症生物标志物. 在本研究中, 我们设计出一种酶激活的近红外苂光探针 (DCM- $\beta$ GlcA), 可在体内和 体外快速、准确地检测GUS的活性. 该探针是由葡萄糖醛酸残基与苂 光基团吡喃腈(DCM)衍生物构成. 在GUS作用下, 该探针在 $680 \mathrm{~nm}$ 处具 有明显的近红外苂光增强，而且它的斯托克位移达到了 $150 \mathrm{~nm}$. 此外, 该探针对于GUS有很高的灵敏度, 检测限低至 $0.19 \mathrm{U} \mathrm{L}^{-1}$. 我们利用该探 针分析了人血清样本中的GUS含量, 其结果与ELISA检测结果一致. 该 探针还可用于示踪活细胞中的GUS，而且能够对荷瘤小鼠体内和肝癌 组织中的GUS进行检测成像. 因此, 该探针可作为检测GUS的理想工具. 